\title{
A re-appraisal of the biological activity of bacteroides LPS
}

\author{
D. M. DELAHOOKE, G. R. BARCLAY* and I. R. POXTON $\dagger$
}

Department of Medical Microbiology, Edinburgh University Medical School, Teviot Place, Edinburgh EH8 9AG and * Blood Transfusion Service, Royal Infirmary, Edinburgh

\begin{abstract}
Summary. Lipopolysaccharides (LPS) were extracted from seven Bacteroides strains by three different techniques: the phenol-water (PW), phenol-chloroform-petroleum (PCP) and Triton- $\mathrm{Mg}^{2+}$ methods. The strains selected included two different $B$. fragilis strains, one of which was grown in two different media. Yields varied between the strains, growth media and extraction technique, but generally the highest yield by weight was from the PCP method and the lowest from the PW method. The PW method was selected for the greatest amounts of carbohydrate and KDO, and the PCP method for the least. Phosphorus levels were more uniform among all extraction methods. Protein contamination was found in all Bacteroides LPS extracts, with extremely low levels in PW-LPS and the highest levels in material extracted by the PCP and Triton- $\mathrm{Mg}^{2+}$ techniques. No protein contamination could be detected after proteinase $\mathrm{K}$ treatment. After silver staining LPS PAGE profiles showed ladder patterns characteristic of smooth LPS for B. vulgatus, B. thetaiotaomicron and the control Escherichia coli $\mathrm{O} 18: \mathrm{K}^{-}$strains, whereas the other Bacteroides strains showed mainly rough and low $\mathbf{M}_{\mathbf{r}}$ material only. The PCP method did not select for high $\mathrm{M}_{\mathrm{r}}$ material in the $B$. fragilis strains; otherwise the LPS profiles for all extraction methods were identical. The biological activities of native and sodium salt form LPS were investigated on a weight for weight basis and compared to that of $E$. coli O18: $\mathrm{K}^{-}$PW-LPS. Amongst the LPS from Bacteroides strains, those prepared by the PW method were found to have a significantly higher activity in a galactosamine mouse lethality model, in induction of TNF and the Limulus amoebocyte lysate (LAL) assay, than LPS extracted by the PCP or Triton- $\mathrm{Mg}^{2+}$ methods. LPS from Bacteroides strains extracted by the PCP method had consistently low activity in all assays. Comparing PW-LPS from Bacteroides strains with that from E. coli $\mathrm{O} 18: \mathrm{K}^{-}$in the galactosamine mouse model, the E. coli O18: $\mathrm{K}^{-}$LPS was $c$. 5000-fold more active than the most active bacteroides LPS. However, in the LAL assay native PW-LPS from both the $B$. fragilis strains, and B. caccae had higher activities (up to 30 -fold) than E. coli $\mathrm{O} 18: \mathrm{K}^{-} \mathrm{LPS}$, with the PW-LPS from the other Bacteroides spp. being up to 15-fold less active than the $E$. coli O18: $\mathrm{K}^{-}$PW-LPS. In the TNF induction assay, E. coli O18: $\mathrm{K}^{-} \mathrm{PW}-\mathrm{LPS}$ was 4-50-fold more active than bacteroides PW-LPS. In the LAL assay and galactosamine mouse model, native LPS had more activity ( $c$. two-fold) than sodium salt form LPS. There was no clear difference in activity between native and sodium salt form LPS in the TNF induction assay. The results for the LAL and TNF induction assay were re-evaluated relative to KDO concentration. In the TNF induction assay, previously low activities seen on a weight for weight basis were due in part to less KDO being present. However, LAL activity for PCP-LPS was still low after re-evaluation relative to KDO concentration. The molecular basis for the differences in biological activity of bacteroides LPS in relation to extraction methods and chemical composition is not yet understood.
\end{abstract}

\section{Introduction}

The gram-negative bacillus Bacteroides fragilis is the anaerobe most frequently isolated from human infec-

Received 9 Feb. 1994; revised version accepted 16 Aug. 1994. $\dagger$ Correspondence should be sent to Dr I. R. Poxton. tions including intra-abdominal, vaginal, brain and lung abscesses and peritonitis. The source is usually the faecal flora. Faeces contain $10^{11}-10^{12}$ bacteria/g and anaerobes constitute $c .99 .9 \%$ of the faecal bacterial mass. Of this, the species belonging to the genus Bacteroides sensu stricto (formerly members of the $B$. fragilis group of Bacteroides) account for $20-30 \%$ of 
the species isolated. ${ }^{1}$ The genus Bacteroides constitutes $B$. fragilis, B. distasonis, B. ovatus, B. thetaiotaomicron, $B$. vulgatus, with $B$. eggerthii, B. uniformis, B. caccae, $B$. merdae and $B$. stercoris being more recently added to the group due to changes in classification. Other species formerly classified as Bacteroides have been reclassified into the genera Porphyromonas and Prevotella $^{2.3}$

In the past 25 years, the lipopolysaccharide (LPS) of $B$. fragilis has been studied by many groups and has yielded many controversial results regarding its rough or smooth structure, and presence of KDO or not, but it is generally agreed that it is weakly endotoxic. ${ }^{4-7} \mathrm{It}$ was thought initially that $B$. fragilis LPS contained no repeating long chains of polysaccharide linked to lipid A core. This was due in part to the use of the phenolchloroform-petroleum extraction method which tends to select for rough type LPS ${ }^{5}$ and it was not recognised that subpopulations existed that expressed different surface molecules. ${ }^{3}$ In $1991^{8}$ Maskell investigated by polyacrylamide gel electrophoresis LPS from 10 species of Bacteroides prepared by the non-selective proteinase $\mathrm{K}$ method. He showed that some $\mathrm{Bac}$ teroides spp. produced predominantly rough LPS whereas others such as $B$. vulgatus and $B$. caccae produced smooth LPS similar to that of facultative enterobacteria. Other species such as $B$. fragilis produced poorly resolved high molecular mass $\left(\mathbf{M}_{\mathrm{r}}\right)$ material as well as rough LPS. It is now well established that $\boldsymbol{B}$. fragilis LPS does contain KDO, but only in a phosphorylated form which renders it undetectable in the standard thiobarbituric acid assay. Prior dephosphorylation by hydrofluoric acid treatment is required for its detection. ${ }^{9}$ It is well documented that the lipid A of $B$. fragilis LPS contains different fatty acids from the lipid A of enterobacterial LPS and is monophosphorylated, and this is one reason why it is less endotoxic than enterobacterial LPS. ${ }^{7}$

Endotoxaemia can occur as a primary event, for example in patients with intra-abdominal or urinary tract sepsis. However, in critically ill patients without a confirmed bacteraemia, it is thought that the gut is the major source of "endotoxin "10 which subsequently leads to the systemic inflammatory response syndrome (SIRS), ${ }^{11}$ a consequence of which can be multiple organ failure and death in up to $80 \%$ of patients. Although it has been shown that the LPS of B. fragilis has lower activity than enterobacterial endotoxin, ${ }^{7}$ Bacteroides spp. are numerically far more predominant (c. 1000-fold) in the gut than enterobacteria such as $E$. coli, thus representing a vast pool of potentially biologically active LPS.

In this paper, the biological activity of LPS from seven species of Bacteroides is re-examined by comparing the activity of LPS extracted by three different methods in mouse lethality and TNF induction models, and an attempt is made to relate activity to chemical composition. The Limulus amoebocyte lysate (LAL) assay was included in the study as the standard in-vitro method for detection of endotoxin.

\section{Materials and methods}

\section{Bacterial strains}

A list of strains used and their origin is shown in table I.

\section{Culture methods}

Bacteria were grown in $15-16-\mathrm{L}$ batches in a $20-\mathrm{L}$ capacity fermenter (LH Engineering, Stoke Poges). Bacteroides spp. were grown in defined broth ${ }^{12}$ or proteose-peptone yeast extract (PPY) broth, anaerobically, in $\mathrm{N}_{2} 100 \%$ at $37^{\circ} \mathrm{C}$. Escherichia coli $\mathrm{O} 18: \mathrm{K}^{-}$ was grown in nutrient broth (NB) anaerobically, in $\mathrm{N}_{2}$ $100 \%$ at $37^{\circ} \mathrm{C}$, or aerobically $\left(\mathrm{pO}_{2} 50 \%\right.$ ) at $37^{\circ} \mathrm{C}$. Strict purity checks were made for each organism at the end of each fermentation run.

\section{Extraction of LPS}

LPS was extracted by the phenol water (PW) method as described by Westphal and Luderitz; ${ }^{13}$ by the phenol-chloroform-petroleum (PCP) method as described by Galanos et al., ${ }^{14}$ and by the Triton- $\mathrm{Mg}^{2+}$ method described by Uchida and Mizushima. ${ }^{15}$ All native LPS $(5 \mathrm{mg} / \mathrm{ml})$ were freed from protein contamination by treating with proteinase $\mathrm{K} 20 \mu \mathrm{g} / \mathrm{ml}$ at $65^{\circ} \mathrm{C}$ for $2 \mathrm{~h}$. Proteinase $\mathrm{K}$ was removed by two washes with pyrogen-free water $\left(\mathrm{PFH}_{2} \mathrm{O}\right)$ at $100000 \mathrm{~g}$. Batches of de-ionised and sodium salt form LPS were prepared by the method of Galanos as described by Hancock and Poxton. ${ }^{16}$ Further native enterobacterial LPS used in the TNF induction assays were obtained from PW or PCP extracts prepared by F. McLoughlin, Department of Medical Microbiology, Edinburgh University Medical School.

\section{Polyacrylamide gel electrophoresis}

Polyacrylamide gels (14\% without SDS) were prepared with the buffer system of Laemmli. ${ }^{17}$ Each extract was dissolved to a concentration of LPS $1 \mathrm{mg} / \mathrm{ml}$ in the SDS-2-mercaptoethanol solubilisation buffer of $\mathrm{Laemmli}^{17}$ and heated at $100^{\circ} \mathrm{C}$ for $3 \mathrm{~min}$. Samples $(20 \mu \mathrm{l})$ were applied to a non-SDS polyacrylamide $14 \%$ gel. To visualise LPS, gels were oxidised with periodate and stained with silver by a method modified from that of Tsai and Frasch. ${ }^{16,18}$ Gels were stained for protein by the Coomassie Blue method as described by Hancock and Poxton. ${ }^{16}$

\section{Chemical analysis of LPS}

Neutral sugars were quantified by the colorimetric method of Dubois et al. ${ }^{19}$ The phosphorus content was measured by the method of Chen et al. ${ }^{20}$ Bacteroides LPS were dephosphorylated by hydrofluoric acid as described by Beckmann et al. ${ }^{9}$ and the KDO content of 
Table I. Bacterial strains

\begin{tabular}{lll}
\hline Species & Strain no. & Origin or source \\
\hline B. fragilis & MPRL 1669 & Appendix, NCTC 9343 \\
B. fragilis & MPRL 1504 & Wound \\
B. vulgatus & MPRL 1985 & Blood \\
B. thetaiotaomicron & MPRL 1720 & Faeces \\
B. caccae & MPRL 1555 & Wound \\
B. uniformis & MPRL 1721 & ?, ATCC 8492 \\
B. ovatus & MPRL 1709 & ?, ATCC 8483 \\
E. coli O18: $\mathrm{K}^{-}$(bort) & MPRL 1274 & Dr A. S. Cross, Walter Reed \\
& & Army Institute for Research, \\
& & Washington DC, USA \\
\hline
\end{tabular}

NCTC, National Collection of Type Cultures, PHLS, Colindale Avenue, London; ATCC, American Type Culture Collection, Rockville, MD, USA; MPRL. departmental stock culture.

Table II. Details of LPS library

\begin{tabular}{|c|c|c|c|c|c|c|}
\hline \multirow[t]{2}{*}{ Strain } & \multirow{2}{*}{$\begin{array}{l}\text { Growth } \\
\text { medium }\end{array}$} & \multirow{2}{*}{$\begin{array}{l}\text { Culture } \\
\text { volume } \\
\text { (L) }\end{array}$} & \multicolumn{4}{|c|}{$\begin{array}{l}\text { Yield from different extraction } \\
\text { methods* }\end{array}$} \\
\hline & & & & PW & PCP & Triton \\
\hline B. fragilis & VT & 16 & 1 & 6.87 & 6.87 & 6.87 \\
\hline \multirow[t]{2}{*}{ NCTC 9343} & & & 2 & $41 \cdot 4$ & $227 \cdot 5$ & $175 \cdot 6$ \\
\hline & & & 3 & 0.60 & $3 \cdot 31$ & 2.56 \\
\hline B. fragilis & PPY & 15 & 1 & $2 \cdot 34$ & $2 \cdot 39$ & $2 \cdot 36$ \\
\hline \multirow[t]{2}{*}{ NCTC 9343} & & & 2 & $37 \cdot 4$ & $99 \cdot 2$ & $47 \cdot 2$ \\
\hline & & & 3 & 1.60 & $4 \cdot 42$ & $2 \cdot 00$ \\
\hline B. fragilis & PPY & 15 & 1 & $2 \cdot 85$ & 2.57 & $2 \cdot 50$ \\
\hline \multirow[t]{2}{*}{ MPRL 1504} & & & 2 & $63 \cdot 7$ & $64 \cdot 5$ & 47.6 \\
\hline & & & 3 & $2 \cdot 24$ & $2 \cdot 51$ & 1.91 \\
\hline B. vulgatus & PPY & 15 & 1 & 2.42 & $2 \cdot 47$ & $2 \cdot 44$ \\
\hline \multirow{2}{*}{ MPRL 1985} & & & 2 & $90 \cdot 7$ & 96.9 & $53 \cdot 2$ \\
\hline & & & 3 & 3.74 & 3.92 & $2 \cdot 18$ \\
\hline B. thetaiotaomicron & PPY & 15 & 1 & $3 \cdot 23$ & 3.67 & 3.77 \\
\hline \multirow[t]{2}{*}{ MPRL 1720} & & & 2 & $29 \cdot 8$ & $103 \cdot 8$ & $83 \cdot 0$ \\
\hline & & & 3 & 0.92 & 2.83 & $2 \cdot 20$ \\
\hline B. caccae & PPY & 15 & 1 & $7 \cdot 40$ & $7 \cdot 63$ & $7 \cdot 50$ \\
\hline \multirow{2}{*}{ MPRL 1555} & & & 2 & $20 \cdot 3$ & 98.6 & $20 \cdot 7$ \\
\hline & & & 3 & 0.27 & 1.29 & $0 \cdot 28$ \\
\hline \multirow{3}{*}{$\begin{array}{l}\text { B. uniformis } \\
\text { MPRL } 1721\end{array}$} & PPY & 15 & 1 & 6.75 & $5 \cdot 21$ & $5 \cdot 60$ \\
\hline & & & 2 & $25 \cdot 8$ & $213 \cdot 4$ & $57 \cdot 7$ \\
\hline & & & 3 & 0.38 & $4 \cdot 24$ & 1.03 \\
\hline \multirow{3}{*}{$\begin{array}{l}\text { B. ovatus } \\
\text { MPRL } 1709\end{array}$} & PPY & 15 & 1 & 3.04 & 3.00 & $2 \cdot 97$ \\
\hline & & & 2 & 54.9 & $124 \cdot 0$ & $73 \cdot 3$ \\
\hline & & & 3 & 0.81 & $4 \cdot 14$ & $2 \cdot 47$ \\
\hline E. coli $\mathrm{O} 18: \mathrm{K}^{-}$ & NB & 15 & 1 & 7.63 & - & - \\
\hline \multirow[t]{2}{*}{ MPRL 1275} & Aerobic & & 2 & $169 \cdot 8$ & - & - \\
\hline & & & 3 & $2 \cdot 23$ & - & - \\
\hline \multirow{3}{*}{$\begin{array}{l}\text { E. coli } \mathrm{O} 18: \mathrm{K}^{-} \\
\text {MPRL } 1275\end{array}$} & NB & 16 & 1 & $1 \cdot 18$ & - & - \\
\hline & Anaerobic & & 2 & 47.5 & - & - \\
\hline & & & 3 & 4.04 & - & - \\
\hline
\end{tabular}

VT, Van Tassell and Wilkins' medium; PPY, proteose-peptone yeast extract broth; NB, nutrient broth; PW, phenol-water; PCP, phenol-chloroform-petroleum.

$* 1$, dry weight of cells $(\mathrm{g}) ; 2$, yield of LPS $(\mathrm{mg}) ; 3, \%$ yield.

all LPS was determined by a modified thiobarbiturate assay. ${ }^{16}$ Protein was measured by the Folin assay. ${ }^{21}$

\section{Mouse lethality: galactosamine model}

D-Galactosamine (12 $\mathrm{mg} / \mathrm{mouse})$ was administered intraperitoneally to groups of three 6-8-week-old male C57 black mice just before intraperitoneal administration of LPS in the range $5 \mathrm{ng}-5 \mu \mathrm{g}$. Survival was recorded up to $24 \mathrm{~h}$. Animal experiments were performed in accordance with Home Office guidelines.
Limulus amoebocyte lysate ( $L A L)$ assay

LPS samples were diluted to ranges of $50-0.5 \mathrm{ng} / \mathrm{ml}$ in $\mathrm{PFH}_{2} \mathrm{O}$. Each sample $(50 \mu \mathrm{l})$ was added in duplicate to wells of microtitration plates (Greiner). Chromogenic LAL reagent (Coatest Endotoxin, Chromogenix, Sweden) was added to each well through a transfer plate to ensure that each well received the LAL reagent at the same time. To minimise error through temperature gradients the outer wells of the plate were left unfilled. The plate was read kinetically every $19 \mathrm{~s}$ at 
a

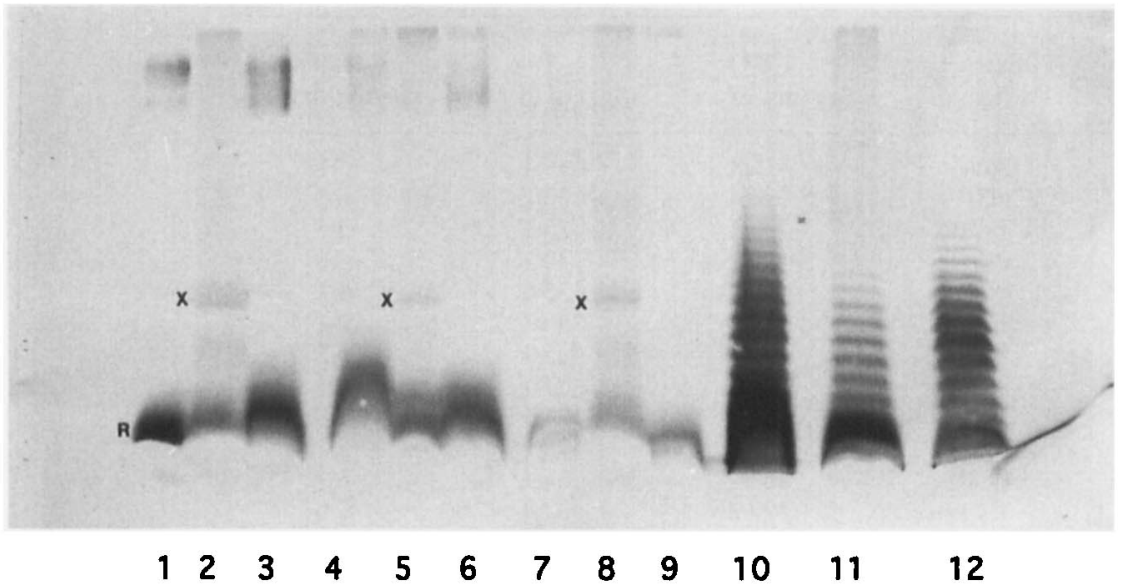

C

b
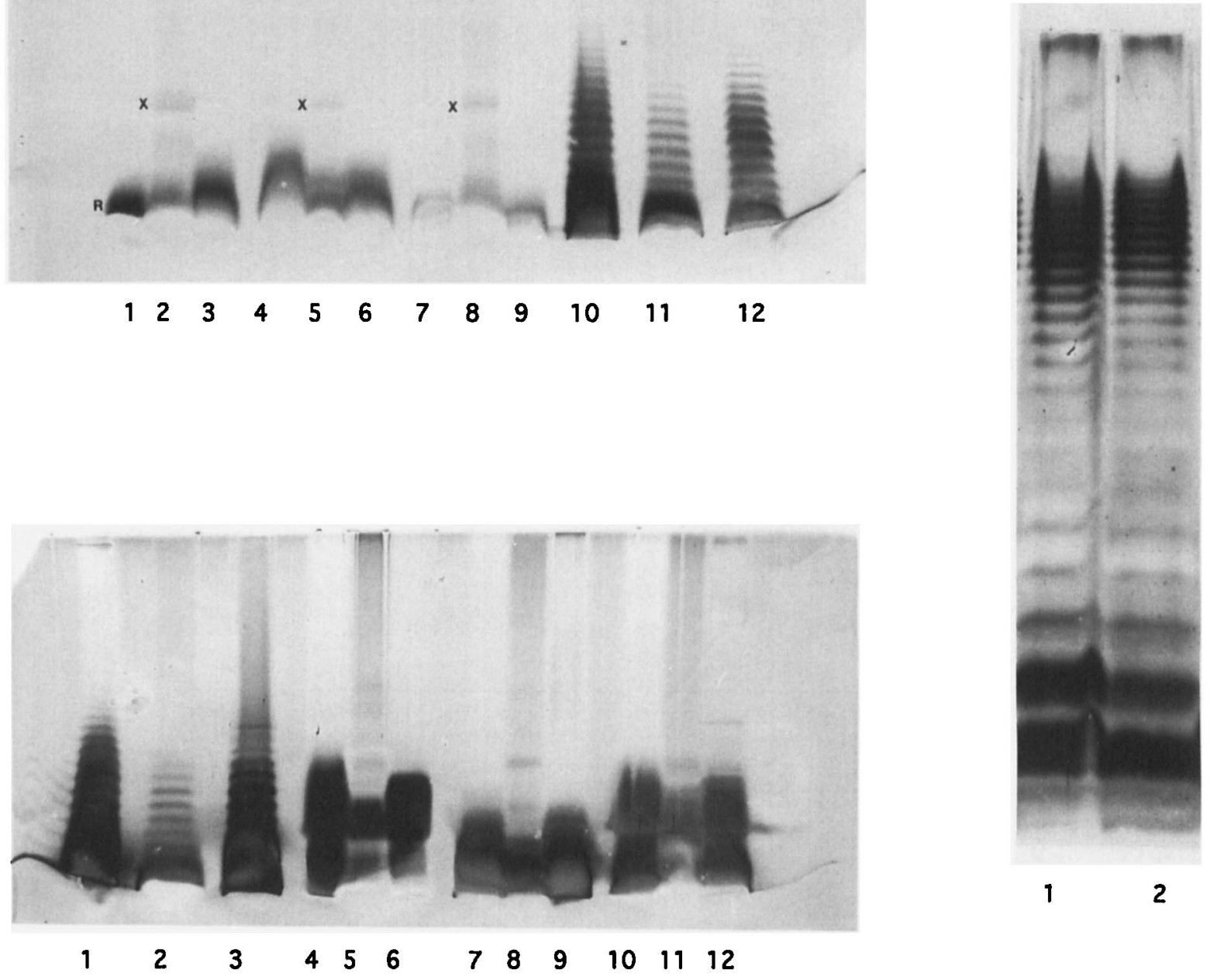

Fig. 1. Silver stain profile of LPS library. R, position of rough LPS; X, band present in PCP preparations. a: track 1, NCTC 9343 VT PW; 2, NCTC 9343 VT PCP; 3, NCTC 9343 VT TRITON; 4, NCTC 9343 PPY PW; 5, NCTC 9343 PPY PCP; 6, NCTC 9343 PPY TRITON; 7, MPRL 1504 PPY PW; 8, MPRL 1504 PPY PCP; 9, MPRL 1504 PPY TRITON; 10, MPRL 1985 PPY PW; 11, MPRL 1985 PPY PCP; 12, MPRL 1985 PPY TRITON. b: track 1, MPRL 1720 PPY PW; 2, MPRL 1720 PPY PCP; 3, MPRL 1720 PPY TRITON; 4, MPRL 1555 PPY PW; 5, MPRL 1555 PPY PCP; 6, MPRL 1555 PPY TRITON; 7, MPRL 1721 PPY PW; 8, MPRL 1721 PPY PCP; 9, MPRL 1721 PPY TRITON; 10, MPRL 1709 PPY PW; 11, MPRL 1709 PPY PCP; 12, MPRL 1709 PPY TRITON. c: track 1, E. coli O18: $\mathrm{K}^{-}$LPS grown aerobically; 2, E. coli $\mathrm{O} 18$ : $\mathrm{K}^{-}$LPS grown anaerobically.

$405 \mathrm{~nm}$ (reference background $650 \mathrm{~nm}$ ) for $90 \mathrm{~min}$ in a Thermomax plate reader (Molecular Devices) at $37^{\circ} \mathrm{C}$. The replicate mean onset time for test samples was standardised against an endotoxin of known potency (E. coli O111:B4, Coatest Kit endotoxin standard, Chromogenix).

\section{LPS-induced TNF secretion}

Mononuclear leucocytes (MNL: c. $30 \%$ monocytes) from freshly collected human buffy coats (obtained from the Blood Transfusion Service, Edinburgh) were prepared by sedimentation on lymphocyte separation medium (ICN Flow). Cells $\left(8 \times 10^{6} / \mathrm{ml}\right)$ were cultured in RPMI 1640 (Blood Transfusion Service, Edinburgh) supplemented with penicillin
$100 \mathrm{U} / \mathrm{ml}$, streptomycin $100 \mu \mathrm{g} / \mathrm{ml}, 1 \mathrm{mM} \mathrm{L}$-glutamine and fetal calf serum (FCS) $10 \%$ in the presence or absence of varying (ng) concentrations of LPS. Culture supernates were collected after $4 \mathrm{~h}$ and stored at $-20^{\circ} \mathrm{C}$ for TNF determination.

\section{Determination of TNF content}

The L929 mouse fibroblast cell line, which is sensitive to TNF, was cultured in growth mediumMEM (Sigma) containing FCS 5\% supplemented with penicillin $100 \mathrm{U} / \mathrm{ml}$, streptomycin $100 \mu \mathrm{g} / \mathrm{ml}$ and $1 \mathrm{mM} \mathrm{L}$-glutamine, and maintained by splitting 1 in 10 twice weekly. Cells were dislodged by a solution of trypsin $0.05 \%$, EDTA $0.02 \%$ to avoid cell clumping, washed and resuspended in a growth medium to 
Table III. Estimation of carbohydrate, phosphorus and KDO content in native LPS samples

\begin{tabular}{|c|c|c|c|c|}
\hline LPS sample/medium & $\begin{array}{l}\text { Extraction } \\
\text { method }\end{array}$ & $\begin{array}{c}\text { CHO } \\
(\mu \mathrm{g} / \mathrm{mg} \text { dry wt })\end{array}$ & $\begin{array}{c}\mathbf{P} \\
(\mu \mathrm{g} / \mathrm{mg} \text { dry wt })\end{array}$ & $\begin{array}{c}\text { KDO } \\
(\mu \mathrm{g} / \mathrm{mg} \text { dry } w \mathrm{t})\end{array}$ \\
\hline B. fragilis & PW & 415.8 & $16 \cdot 4$ & $7 \cdot 8$ \\
\hline \multirow[t]{2}{*}{ NCTC 9393/VT } & PCP & $614 \cdot 4$ & $33 \cdot 1$ & 0.8 \\
\hline & Triton & $229 \cdot 2$ & $29 \cdot 3$ & $3 \cdot 5$ \\
\hline B. fragilis & PW & $172 \cdot 2$ & $39 \cdot 2$ & 3.8 \\
\hline \multirow[t]{2}{*}{ NCTC 9343/PPY } & PCP & 90.8 & 33.6 & 1.4 \\
\hline & Triton & 147.8 & $49 \cdot 0$ & $2 \cdot 1$ \\
\hline B. fragilis & PW & $198 \cdot 2$ & $55 \cdot 3$ & 6.2 \\
\hline \multirow[t]{2}{*}{ MPRL 1504/PPY } & PCP & $120 \cdot 8$ & $72 \cdot 4$ & 0.5 \\
\hline & Triton & $130 \cdot 0$ & $28 \cdot 5$ & 3.7 \\
\hline B. vulgatus & PW & 267.6 & 78.9 & 2.7 \\
\hline \multirow[t]{2}{*}{ MPRL 1985/PPY } & PCP & $67 \cdot 4$ & $47 \cdot 4$ & 0.9 \\
\hline & Triton & 197.2 & 37.8 & $2 \cdot 6$ \\
\hline B. thetaiotaomicron & PW & $363 \cdot 8$ & $54 \cdot 2$ & - \\
\hline \multirow[t]{2}{*}{ MPRL 1720/PPY } & РCP & $43 \cdot 8$ & $47 \cdot 4$ & $0 \cdot 4$ \\
\hline & Triton & $262 \cdot 4$ & $79 \cdot 6$ & $4 \cdot 0$ \\
\hline B. caccae & PW & $240 \cdot 2$ & $54 \cdot 3$ & - \\
\hline \multirow[t]{2}{*}{ MPRL $1555 /$ PPY } & PCP & 29.6 & 33.8 & - \\
\hline & Triton & 148.6 & 24.9 & - \\
\hline B. uniformis & PW & $221 \cdot 6$ & $102 \cdot 0$ & - \\
\hline \multirow[t]{2}{*}{ MPRL 1721/PPY } & PCP & $53 \cdot 0$ & $38 \cdot 2$ & - \\
\hline & Triton & $173 \cdot 4$ & $85 \cdot 5$ & - \\
\hline B. ovatus & PW & $281 \cdot 0$ & $43 \cdot 1$ & $5 \cdot 7$ \\
\hline \multirow[t]{2}{*}{ MPRL 1709/PPY } & PCP & $110 \cdot 8$ & $39 \cdot 6$ & $1 \cdot 1$ \\
\hline & Triton & $178 \cdot 0$ & $41 \cdot 6$ & $2 \cdot 4$ \\
\hline $\begin{array}{l}\text { E. coli } \mathrm{O} 18: \mathrm{K}^{-} / \\
\mathrm{NB} \text { aerobic }\end{array}$ & $\mathrm{PW}$ & 254.8 & $36 \cdot 5$ & $2 \cdot 2$ \\
\hline $\begin{array}{l}\text { E. coli } \mathrm{O} 18: \mathrm{K}^{-} / \\
\mathrm{NB} \text { anaerobic }\end{array}$ & PW & $260 \cdot 0$ & $34 \cdot 0$ & $2 \cdot 4$ \\
\hline
\end{tabular}

PW, phenol-water; PCP, phenol-chloroform-petroleum; VT, Van Tassell and Wilkins' medium; PPY, proteose-peptone yeast extract broth; NB, nutrient broth; $\mathrm{CHO}$, carbohydrate; P, phosphorus; - - not done. All assays were repeated on at least two occasions and the results presented are the mean of two experiments. All samples were tested in duplicate for each experiment.

$3 \times 10^{5}$ cells $/ \mathrm{ml}$. Cells were dispensed in flat-bottomed microtitration plates (Greiner) at $100 \mu \mathrm{l} /$ well and incubated in $\mathrm{CO}_{2} 5 \%$ at $37^{\circ} \mathrm{C}$ for $20 \mathrm{~h}$. The growth medium was then aspirated, discarded and replaced with $100 \mu \mathrm{l}$ /well of assay medium-MEM containing FCS $5 \%$ supplemented with $1 \mathrm{mM}$ glutamine and actinomycin-D (to stop further cell growth without killing the cells) $2 \mu \mathrm{g} / \mathrm{ml}$. To experimental wells, $100 \mu \mathrm{l}$ of test supernate diluted 1 in 5 in assay medium was added. A standard of recombinant TNF (National Institute for Biological Standards and Controls) diluted serially 1 in 5 from a starting concentration of $1000 \mathrm{IU} / \mathrm{ml}$ and wells without TNF were included. Plates were sealed and incubated in $\mathrm{CO}_{2} 5 \%$ at $37^{\circ} \mathrm{C}$ for $24 \mathrm{~h}$. The medium was then discarded and replaced with filtered $(0.22 \mu \mathrm{m})$ crystal violet solution (crystal violet $0.5 \%$ in methanol $20 \% \mathrm{v} / \mathrm{v}$ in distilled water) $100 \mu \mathrm{l} /$ well which stains surviving cells. After $2 \mathrm{~min}$, the plates were washed vigorously under tap water and dried. The crystals were dissolved by addition of $100 \mu \mathrm{l}$ of acetic acid $20 \% \mathrm{v} / \mathrm{v}$ to all wells and the plate was read at $585 \mathrm{~nm}$ on a Vmax plate reader (Molecular Devices). The content of TNF was calculated relative to the standard curve.

\section{Results}

\section{Comparison of different extraction methods}

The yield of native LPS obtained with each extraction method is shown in table II. The PCP extraction method gave the highest yield of LPS for each organism, whereas the PW method gave the lowest yield for most organisms. Those organisms that gave a high yield of dry cells were very mucoid and the yield of LPS was generally poorer.

Polyacrylamide gels were run and stained for LPS and protein. Contaminating protein was found in bacteroides LPS extracted by all three methods, especially those extracted by the PCP and Triton methods (data not shown). LPS extracts were assayed for protein content $:^{21}$ in PCP extracts protein content ranged from undetectable to $>200 \mu \mathrm{g} / \mathrm{mg}$ dry weight; in all Triton preparations, with the exception of that from B. vulgatus MPRL 1985 in which none was detected, protein contamination was in the range $60-500 \mu \mathrm{g} / \mathrm{mg}$ dry weight; and none was detectable in the PW extracts.

All LPS preparations were then treated with proteinase $\mathrm{K}$. On repeating the protein assays, none was detected and no Coomassie Blue-staining material was 
Table IV. LPS-induced mouse lethality (galactosamine model)

\begin{tabular}{|c|c|c|c|c|c|}
\hline \multirow{2}{*}{ LPS sample } & \multicolumn{5}{|c|}{ Number of survivors after } \\
\hline & $5 \mathrm{ng}$ & $50 \mathrm{ng}$ & $5 \mu \mathrm{g}$ & $10 \mu \mathrm{g}$ & $20 \mu \mathrm{g}$ \\
\hline B. fragilis NCTC 9343 VT PW & - & - & $3 / 3$ & $1 / 3$ & $0 / 3$ \\
\hline B. fragilis NCTC 9343 PPY PW & - & - & $3 / 3$ & $2 / 3$ & $1 / 3$ \\
\hline B. fragilis MPRL 1504 PW & - & - & $3 / 3$ & $3 / 3$ & $2 / 3$ \\
\hline B. vulgatus MPRL 1985 PW & 一 & - & $3 / 3$ & $3 / 3$ & $0 / 3$ \\
\hline B. thetaiotaomicron MPRL 1720 PW & - & - & $3 / 3$ & $3 / 3$ & $1 / 3$ \\
\hline B. caccae MPRL $1555 \mathrm{PW}$ & - & - & $3 / 3$ & $3 / 3$ & $1 / 3$ \\
\hline B. uniformis MPRL 1721 PW & - & 一 & $3 / 3$ & $3 / 3$ & $3 / 3$ \\
\hline B. ovatus MPRL 1709 PW & - & - & $3 / 3$ & $3 / 3$ & $3 / 3$ \\
\hline B. fragilis NCTC 9343 PPY PCP & - & - & $3 / 3$ & $3 / 3$ & $3 / 3$ \\
\hline B. fragilis NCTC 9343 PPY Triton & - & - & $3 / 3$ & $3 / 3$ & $3 / 3$ \\
\hline * B. fragilis NCTC 9343 PPY PW & - & - & $3 / 3$ & $2 / 3$ & $0 / 3$ \\
\hline * B. fragilis NCTC 9343 PPY PCP & - & - & $3 / 3$ & $3 / 3$ & $3 / 3$ \\
\hline * B. fragilis NCTC 9343 PPY Triton & - & - & $3 / 3$ & $3 / 3$ & $3 / 3$ \\
\hline E. coli $\mathrm{O} 18: \mathrm{K}^{-}$aerobic $\mathrm{PW}$ & $3 / 3$ & $0 / 3$ & $0 / 3$ & - & - \\
\hline E. coli $\mathrm{O} 18: \mathrm{K}^{-}$anaerobic $\mathrm{PW}$ & $3 / 3$ & $0 / 3$ & $0 / 3$ & - & - \\
\hline
\end{tabular}

All LPS are native samples unless indicated.

* Sodium salt form LPS; see table III for other abbreviations.

Table V. Endotoxic activities of sodium salt and native LPS $(5 \mathrm{ng} / \mathrm{ml})$ samples

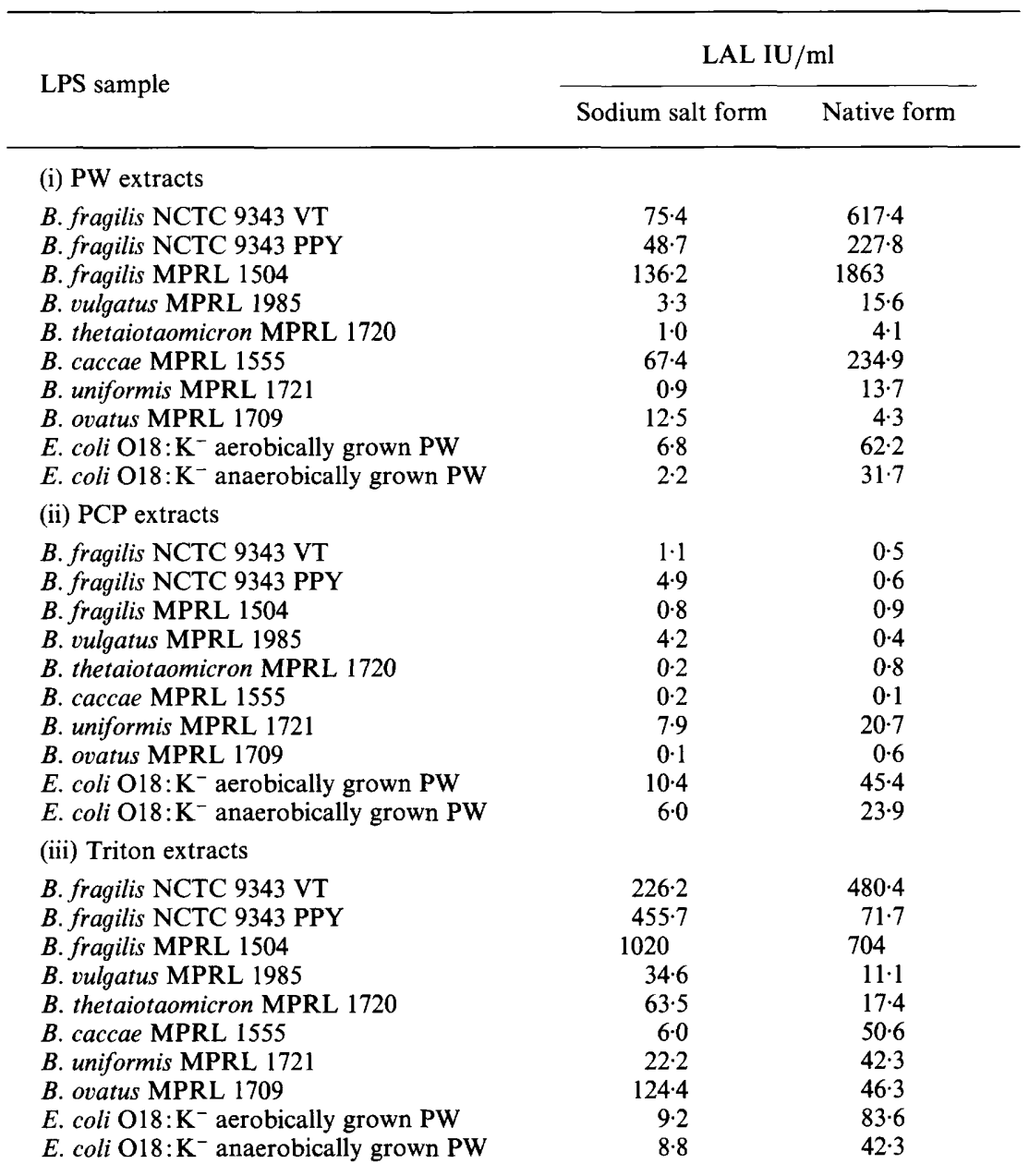

All assays were repeated on at least two occasions and the results presented are the mean of two experiments. All samples were tested in duplicate for all assays. See table III for abbreviations. 


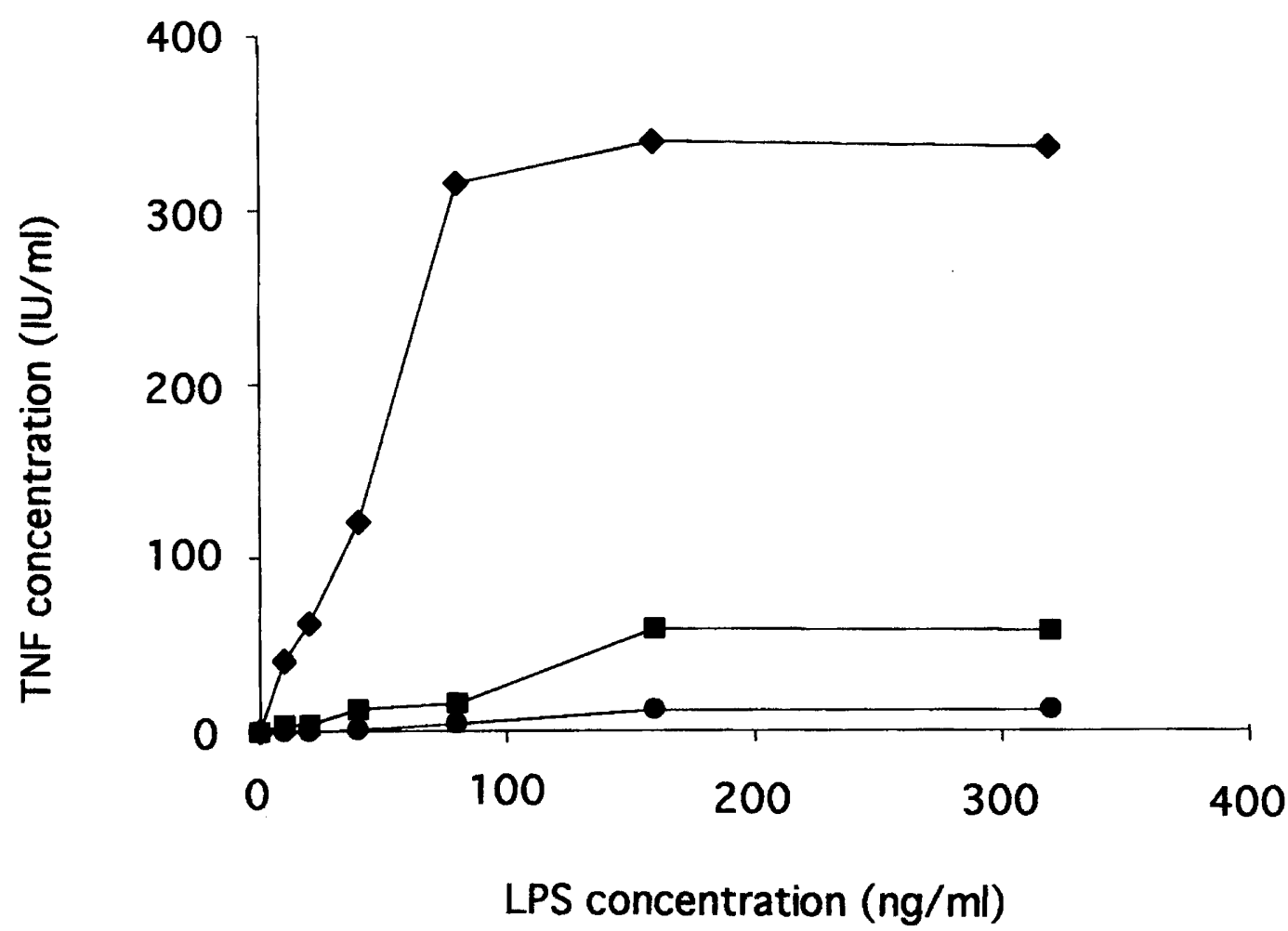

Fig. 2. TNF concentration ( $\mathrm{IU} / \mathrm{ml})$ from human mononuclear leucocytes $\left(8 \times 10^{6}\right.$ cells $\left./ \mathrm{ml}\right)$ after stimulation for $4 \mathrm{~h}$ with $B$. fragilis $\mathrm{NCTC}$ 9343 PPY ( $(\mathbf{)})$ B. vulgatus MPRL $1985(\bigcirc)$ and aerobically grown E. coli $\mathrm{O} 18: \mathrm{K}^{-}(\diamond)$ native LPS samples extracted by the PW method. Each point is the mean of two readings.

observed in PAGE. LPS profiles after silver staining were identical to those before proteinase $\mathrm{K}$ treatment (data not shown). The following results are from LPS preparations which had been treated with proteinase $\mathrm{K}$ to remove protein contamination.

Fig. 1 shows LPS profiles on PAGE for each strain and extraction method after separation and silver staining. A banding pattern typical of smooth LPS was seen for $E$. coli $\mathrm{O} 18: \mathrm{K}^{-}$(gel c, tracks 1 and 2), B. vulgatus MPRL 1985 (gel a, tracks 10,11 and 12) and B. thetaiotaomicron MPRL 1720 (gel b, tracks 1, 2 and 3). Material of high $M_{r}$ was seen in $B$. fragilis LPS extracted by both the PW and Triton methods. Rough, low $M_{r}$ material was seen in extracts prepared for all species by each method, and was "dumbbell shaped" for B. caccae and B. ovatus (gel b, tracks 4, 5 and 6 , and 10,11 and 12). The PCP extraction method produced a pronounced band $(\mathrm{X})$ present behind the main front band $(\mathrm{R})$ in all preparations. For $B$. fragilis, the PCP extraction method did not select for high $\mathrm{M}_{\mathrm{r}}$ material. Silver stain profiles for sodium salt form LPS were identical to profiles of native forms (data not shown). LPS profiles for $E$. coli $\mathrm{O} 18: \mathrm{K}^{-}$grown aerobically and anaerobically were identical.

\section{Chemical analysis of LPS samples}

Samples of dry extract were resuspended in $\mathrm{PFH}_{2} \mathrm{O}$ to a concentration of $5 \mathrm{mg} / \mathrm{ml}$ and assayed for carbohydrate, phosphorus and KDO content. The relative amounts of carbohydrate, phosphorus and
$\mathrm{KDO}$ are shown in table III. Bacteroides spp. showed a negligible amount or no KDO content before treatment with hydrofluoric acid. The PW extraction method selected for the greatest amount of carbohydrate and KDO material and the PCP extraction method for the least. Phosphorus levels were more uniform among all extraction methods. No difference was observed between LPS extracts from $E$. coli O18: $\mathrm{K}^{-}$grown in different atmospheres.

\section{LPS induced mouse lethality (galactosamine model)}

E. coli $\mathrm{O} 18: \mathrm{K}^{-}$LPS was lethal to all mice at $50 \mathrm{ng} /$ mouse (table IV) whereas $B$. fragilis NCTC 9343 VT PW-LPS and B. vulgatus MPRL 1985 PWLPS were only lethal to mice at $20 \mu \mathrm{g} /$ mouse. No difference in lethality was seen for native and sodium salt form $B$. fragilis NCTC 9343 VT PW-LPS. Mice were not killed by the maximum dose of $B$. fragilis LPS extracted by PCP or Triton, nor by $B$. uniformis and $B$. ovatus LPS extracted by PW.

\section{Reactivity of LPS samples in LAL assay}

Endotoxic activities in the LAL assay of native and sodium salt form LPS are illustrated in table V (i), (ii) and (iii) for each extraction method. On a weight for weight basis, the greatest activity was seen in the PW extracts and the least activity seen in the PCP extracts. Most native PW-LPS were more active than sodium 
Table VI. Measured TNF concentration from human MNL $\left(8 \times 10^{6}\right.$ cells $\left./ \mathrm{ml}\right)$ after stimulation for $4 \mathrm{~h}$ with native and sodium salt form LPS $(50 \mathrm{ng} / \mathrm{ml})$ from $E$. coli O18: $\mathrm{K}^{-}$and Bacteroides spp. extracted by three different methods

\begin{tabular}{|c|c|c|c|}
\hline \multirow{2}{*}{ LPS sample } & \multirow{2}{*}{$\begin{array}{l}\text { Extraction } \\
\text { method }\end{array}$} & \multicolumn{2}{|c|}{ TNF concentration $(\mathrm{IU} / \mathrm{ml})$} \\
\hline & & Native LPS & Sodium salt LPS \\
\hline \multirow[t]{3}{*}{ B. fragilis NCTC 9343 VT } & PW & $23 \cdot 16$ & 11.92 \\
\hline & PCP & $0 \cdot 30$ & 0.71 \\
\hline & Triton & 2.99 & 1.07 \\
\hline \multirow[t]{3}{*}{ B. fragilis NCTC 9343 PPY } & PW & $18 \cdot 81$ & $4 \cdot 60$ \\
\hline & PCP & 2.53 & 1.78 \\
\hline & Triton & 0.51 & $0 \cdot 31$ \\
\hline \multirow[t]{3}{*}{ B. fragilis MPRL 1504} & PW & 4.93 & $2 \cdot 51$ \\
\hline & PCP & $0 \cdot 42$ & 0.25 \\
\hline & Triton & 0.99 & $0 \cdot 47$ \\
\hline \multirow[t]{3}{*}{ B. vulgatus MPRL 1985} & PW & $2 \cdot 58$ & 0.72 \\
\hline & PCP & $0 \cdot 15$ & 0.51 \\
\hline & Triton & 0.39 & $0 \cdot 31$ \\
\hline \multirow[t]{3}{*}{ B. thetaiotaomicron MPRL 1720} & PW & $6 \cdot 40$ & $6 \cdot 47$ \\
\hline & PCP & 0.03 & 0.43 \\
\hline & Triton & $0 \cdot 17$ & 0.49 \\
\hline \multirow[t]{3}{*}{ B. caccae MPRL 1555} & PW & 13.89 & $15 \cdot 25$ \\
\hline & PCP & 0.22 & 0.74 \\
\hline & Triton & $2 \cdot 48$ & $2 \cdot 44$ \\
\hline \multirow[t]{3}{*}{ B. uniformis MPRL 1721} & PW & $10 \cdot 10$ & $35 \cdot 34$ \\
\hline & PCP & $4 \cdot 81$ & $4 \cdot 81$ \\
\hline & Triton & $10 \cdot 87$ & $5 \cdot 09$ \\
\hline \multirow[t]{3}{*}{ B. ovatus MPRL 1709} & PW & 8.66 & 13.89 \\
\hline & PCP & 1.44 & $5 \cdot 37$ \\
\hline & Triton & $1 \cdot 25$ & $2 \cdot 32$ \\
\hline E. coli $\mathrm{O} 18: \mathrm{K}^{-}$aerobically grown & PW & $94 \cdot 61$ & $43 \cdot 21$ \\
\hline E. coli $\mathrm{O} 18: \mathrm{K}^{-}$anaerobically grown & PW & $99 \cdot 00$ & $43 \cdot 21$ \\
\hline E. coli $\mathrm{O} 6$ & PW & $59 \cdot 00$ & - \\
\hline E. coli $\mathrm{O} 12$ & PW & $58 \cdot 20$ & - \\
\hline E. coli $\mathrm{O} 15$ & PW & 68.96 & - \\
\hline K. pneumoniae M10B & PW & $48 \cdot 21$ & - \\
\hline E. coli $\mathrm{J} 5$ & PCP & 36.63 & - \\
\hline E. coli $\mathrm{K} 12$ & PCP & $49 \cdot 90$ & - \\
\hline S. minnesota $\mathbf{R a}$ & PCP & 31.68 & - \\
\hline S. minnesota $\mathrm{Rb}$ & PCP & $96 \cdot 70$ & - \\
\hline S. minnesota $\mathrm{Rc}$ & PCP & $49 \cdot 90$ & - \\
\hline S. minnesota $\mathrm{Rd}$ & PCP & 78.45 & - \\
\hline$S$. minnesota $\operatorname{Re}$ & PCP & $50 \cdot 48$ & - \\
\hline
\end{tabular}

All assays were carried out on at least two occasions and the results presented are the mean of two experiments. All samples were tested in duplicate for each assay. See table III for abbreviations.

salt PW-LPS. Approximately $70 \%$ of native PCP-LPS are more active than sodium salt PCP-LPS. No significant difference was seen between the native and sodium salt form LPS extracted by Triton. LPS from E. coli $\mathrm{O} 18: \mathrm{K}^{-}$grown aerobically was more active than LPS from $E$. coli $\mathrm{O} 18$ : $\mathrm{K}^{-}$grown anaerobically by a factor of two. B. fragilis MPRL 1504 PW-LPS was more active than $E$. coli $\mathrm{O} 18: \mathrm{K}^{-}$LPS by a factor of 30, B. fragilis NCTC 9343 VT PW-LPS by a factor of 10, B. fragilis NCTC 9343 PPY PW-LPS by a factor of four and B. caccae MPRL 1555 PW-LPS by a factor of four. LPS from all other Bacteroides spp. were less active than that from $E$. coli $\mathrm{O} 18: \mathrm{K}^{-}$. A difference in activity for $B$. fragilis NCTC 9343 LPS grown in different media was also seen.

\section{LPS-induced TNF secretion from human buffy coats}

The amount of TNF induced by different LPS from human MNL $\left(8 \times 10^{6}\right.$ cells $\left./ \mathrm{ml}\right)$ at several different concentrations is shown in fig. 2. TNF appears to reach a maximal level at $c .160 \mathrm{ng}$ of LPS for all those tested. Based on the data from fig. 2, an LPS concentration of $50 \mathrm{ng} / \mathrm{ml}$ was selected to compare a larger panel of LPS from other Bacteroides spp. and enterobacteria (table VI). This value was chosen as it was in the middle of the linear part of both the dose response curve and the standard curve of the assay. This would not show the maximum induction capacity of the LPS but was a compromise for comparing a large number of LPS samples. E. coli O18: $\mathrm{K}^{-}$LPS stimulated the most TNF production with no difference in TNF production between LPS from $E$. coli O18: $\mathrm{K}^{-}$grown aerobically or anaerobically. On a weight for weight basis, PW-LPS stimulated the greatest TNF production. Comparing PW-LPS, bacteroides LPS induced TNF much less than did E. coli O18: $\mathrm{K}^{-} \mathrm{LPS}$, with the most active (B. fragilis $\mathrm{NCTC}$ 9343 VT) being four times less active than $E$. coli O18: $\mathrm{K}^{-}$and the least active (B. vulgatus MPRL 1985) 
Table VII. TNF concentration from human MNL and endotoxic activity after stimulation with LPS from selected Bacteroides spp. and E. coli $018: \mathrm{K}^{-}$LPS relation to KDO content

\begin{tabular}{|c|c|c|c|}
\hline LPS sample & $\begin{array}{l}\text { Extraction } \\
\text { method }\end{array}$ & $\begin{array}{l}\text { TNF stimulation } \\
\text { (IU/ng of KDO) }\end{array}$ & $\begin{array}{c}\text { LAL activity } \\
\text { (EU/ng of KDO) }\end{array}$ \\
\hline \multirow[t]{3}{*}{ B. fragilis NCTC $9343 \mathrm{VT}$} & PW & $59 \cdot 38$ & 1583.08 \\
\hline & PCP & $7 \cdot 16$ & $10 \cdot 69$ \\
\hline & Triton & $17 \cdot 3$ & 2784.93 \\
\hline \multirow[t]{3}{*}{ B. fragilis NCTC 9343 PPY } & PW & $46 \cdot 11$ & $1191 \cdot 11$ \\
\hline & PCP & $35 \cdot 11$ & 8.44 \\
\hline & Triton & 4.90 & $693 \cdot 24$ \\
\hline \multirow[t]{3}{*}{ B. fragilis MPRL 1504} & PW & 15.85 & 5985.54 \\
\hline & PCP & $17 \cdot 42$ & $37 \cdot 38$ \\
\hline & Triton & 5.38 & $3846 \cdot 99$ \\
\hline \multirow[t]{3}{*}{ B. vulgatus MPRL 1985} & PW & $19 \cdot 11$ & 115.48 \\
\hline & PCP & 3.41 & 7.93 \\
\hline & Triton & 3.00 & $84 \cdot 67$ \\
\hline \multirow[t]{3}{*}{ B. thetaiotaomicron MPRL 1720} & PW & - & - \\
\hline & PCP & 1.55 & $42 \cdot 61$ \\
\hline & Triton & 8.64 & 867.91 \\
\hline \multirow{3}{*}{ B. ovatus MPRL 1709} & PW & $30 \cdot 37$ & 14.98 \\
\hline & PCP & 25.89 & $4 \cdot 68$ \\
\hline & Triton & $10 \cdot 43$ & $385 \cdot 5$ \\
\hline $\begin{array}{l}\text { E. coli } \mathrm{O} 18: \mathrm{K}^{-} \\
\text {aerobic }\end{array}$ & PW & $502 \cdot 16$ & $572 \cdot 32$ \\
\hline $\begin{array}{l}\text { E. coli } \mathrm{O} 18: \mathrm{K}^{-} \\
\text {anaerobic }\end{array}$ & PW & $485 \cdot 60$ & $261 \cdot 15$ \\
\hline
\end{tabular}

See table III for abbreviations.

being 37 times less active than E. coli $\mathrm{O} 18: \mathrm{K}^{-}$. TNF production with other enterobacterial LPS tested was of the same level or less than that with E. coli $\mathrm{O} 18: \mathrm{K}^{-}$ LPS, all being more active than bacteroides LPS. Sodium salt form $E$. coli $\mathrm{O} 18: \mathrm{K}^{-}$LPS had half the activity of native form $E$. coli $\mathrm{O} 18: \mathrm{K}^{-}$LPS. Generally for bacteroides LPS there was no clear distinction in activity between sodium salt and native form LPS.

\section{Reactivity of LPS samples on the basis of KDO concentration}

All the above assays were done on a weight for weight basis. However, because endotoxicity is likely to depend on lipid A concentration, it was decided to re-evaluate some of the results of TNF induction and LAL activity relative to KDO concentration in an attempt to compare lipid A levels-on the assumption (which could well be false) that lipid A is proportional to $\mathrm{KDO}$ in all species.

The TNF concentration from human buffy coats expressed as IU/ng of KDO and endotoxic activity in LAL expressed as EU/ng of KDO after stimulation with selected bacteroides and E. coli $\mathrm{O} 18: \mathrm{K}^{-}$LPS is presented in table VII. For the TNF concentrations measured, this shows that the low activities seen previously on a weight for weight basis (table VI) were due in part to less KDO being present. However, LAL activity for PCP-extracted LPS was still low when the results were represented/ng of KDO.

\section{Discussion}

This study has shown that an aqueous phenol (PW) extract of bacteroides LPS is significantly different both in terms of chemical composition and biological activity from the PCP or Triton products. The three methods were selected in an attempt to produce products of different composition. The classical PW method was likely to select for higher $M_{r}$, less hydrophobic material, the PCP method for roughform, more hydrophobic material, and the Triton$\mathrm{Mg}^{2+}$ method was chosen as a milder, less selective method. It is well accepted that enterobacterial LPS is heterogeneous in $\mathbf{M}_{\mathrm{r}}$ even when pure. We acknowledge that the bacteroides "LPS" used in this study may be heterogeneous both in $\mathbf{M}_{\mathbf{r}}$ and in molecular composition. The degree of different molecular species of LPS and other co-purifying carbohydrate, due to the probable subpopulation structure of our cultures, ${ }^{3}$ is by no means certain. The biological activity of enterobacterial LPS is thought to depend on its solubility ${ }^{22}$ and, for this reason, the native and the standardised, soluble sodium salt forms were prepared from electrodialysed material.

Our results agree with previous studies ${ }^{7}$ that in a mouse lethality model bacteroides LPS is $c$. 5000 -fold less active than LPS from $E$. coli . In past studies, ${ }^{7,23,24}$ bacteroides LPS has been quoted as being 100-1000fold less biologically active in vitro, depending on the assay, than LPS from enterobacteria. Our results for bacteroides LPS extracted by the PCP or Triton method agree with this. However, our results for LPS 
extracted by the PW method disagree with the accepted view.

Tumour necrosis factor-alpha (TNF) is considered to be the pivotal cytokine in the host response to endotoxin. In the TNF induction assay, $E$. coli O18: $\mathrm{K}^{-}$LPS was only four-fold more active than $B$. fragilis LPS, seven-fold more than $B$. caccae LPS and up to 50-fold more than the other bacteroides LPS. In the LAL assay, which has questionable value for the in-vivo situation, the same LPS that were the most active in the TNF-induction assay (from $B$. fragilis and $B$. caccae) were $30-40$-fold more active than $E$. coli O18: $\mathrm{K}^{-}$LPS, with $E$. coli $\mathrm{O} 18: \mathrm{K}^{-}$LPS being $c$. 10fold more active than the rest of the bacteroides LPS tested. The two-fold difference in activity in the LAL assay for LPS from $E$. coli $\mathrm{O} 18: \mathrm{K}^{-}$grown aerobically and anaerobically is unclear. Our results also show that solubility (native versus sodium salt form LPS) does not play an important role in biological activity as has been described previously for enterobacterial LPS $;^{22}$ in most cases the sodium salt form was of lower activity. Growth in the defined van Tassell and Wilkins' medium was included because we have found recently that growth in this medium converts several B. fragilis strains, including NCTC 9343, from being sensitive to the lytic action of normal human serum to being resistant. This may be due to a change in expression of certain surface polymers such as LPS. ${ }^{25}$ The results show some differences between the two growth media in respect to both chemical composition and biological activities.

The possibility that some contaminant may be present in the LPS preparations from Bacteroides spp. must be considered. In this connection we found no contaminating organisms when culturing the organisms for extraction and the identity of each strain of Bacteroides was confirmed before the start of the study. Furthermore, PW-LPS samples from several Bacteroides spp. prepared by different individuals at different times in our laboratory were tested alongside our own samples in the LAL and TNF induction assay. They were found to produce nearly identical results (data not shown). Higher biological activity in the PW preparations cannot be due to a biologically active protein as protein levels were negligible after purification (table III). Biological activity also cannot be due to any contaminating proteinase $\mathrm{K}$ as all bacteroides LPS had been treated similarly with proteinase $\mathrm{K}$.

Some PW preparations of bacteroides LPS are clearly more active than others, e.g., $B$. fragilis NCTC 9343 VT/PPY and $B$. caccae MPRL 1555. Chemical analysis does not explain why the LPS from some species are more active than from others. It does show that more carbohydrate and KDO is present in the PW preparations. The amount of KDO destroyed or not released by hydrofluoric acid treatment is not known. Those species that had a low reactivity in the LAL and TNF bioassays (B. vulgatus MPRL 1985 and $B$. thetaiotaomicron MPRL 1720) had a smooth LPS profile on PAGE (fig. 1). This is in apparent contradiction to the view that aqueous phenol preferentially extracts smooth-form LPS. Moreover it is surprising that those strains which are obviously smooth (e.g., B. vulgatus) are less endotoxic.

In the light of the great variation found in the chemical analyses, PAGE profiles and biological activities of the various preparations, and the knowledge that several different LPS-like molecules have been identified by monoclonal antibodies, ${ }^{26}$ the suggestion that different extraction methods selectively produce different populations of LPS or perhaps lipid-linked capsular polysaccharides is strong. In nature all of these different molecular species, if expressed, might contribute towards a range of "endotoxic" phenomena. Therefore, it is essential to be able to purify the various components of this heterogeneous "LPS" population and relate them to biological function.

The role of bacteroides LPS in endotoxic shock remains to be defined. We have shown that PWextracted LPS has a higher biological activity than previously reported. ${ }^{7,24}$ How these chemically extracted "LPS" relate to what is found in vivo also needs to be defined. When we consider that Bacteroides spp. are in vast excess of $E$. coli in the gut and may have higher biological activity than previously thought, the bacteroides LPS may play an important but neglected role in endotoxic shock.

This work was funded by a grant from the Medical Research Council No. G92104905B. We thank R. Brown and J. Verth for their technical assistance.

\section{References}

1. Duerden BI, Drasar BS (eds). Anaerobes in human disease London, Edward Arnold: 1991.

2. Shah HN, Collins MD. Proposal to restrict the genus Bacteroides to Bacteroides fragilis and closely related species. Int $J$ Syst Bacteriol 1989; 39: 85-87.

3. Patrick S. The virulence of Bacteroides fragilis. Rev Med Microbiol 1993; 4: 40-49.

4. Kasper DL, Weintraub A, Lindberg AA, Lonngren J. Capsular polysaccharides and lipopolysaccharides from two Bacteroides fragilis reference strains: chemical and immunochemical characterization. J Bacteriol 1983; 153: 991-997.

5. Poxton IR, Brown R. Immunochemistry of the surface carbo-

hydrate antigens of Bacteroides fragilis and definition of a common antigen. $J$ Gen Microbiol 1986; 132 : 2475-2481.

6. Weintraub A, Larsson BE, Lindberg AA. Chemical and immunochemical analyses of Bacteroides fragilis lipopolysaccharides. Infect Immun 1985; 49: 197-201.

7. Lindberg AA, Weintraub A, Zähringer U, Rietschel ET. Structure-activity relationships in lipopolysaccharides of Bacteroides fragilis. Rev Infect Dis 1990; 12 Suppl 2: S133-S141.

8. Maskell JP. The resolution of bacteroides lipopolysaccharides by polyacrylamide gel electrophoresis. $J$ Med Microbiol 1991; 34: 253-257.

9. Beckmann I, van Eijk HG, Meisel-Mikokijczyk F, Wallenburg HC. Detection of 2-keto-3-deoxyoctonate in endotoxins 
isolated from six reference strains of the Bacteroides fragilis group. Int J Biochem 1989; 21: 661-666.

10. Runcie C, Ramsay G. Intraabdominal infection: pulmonary failure. World J Surg 1990; 14: 196-203.

11. Bone RC. Toward an epidemiology and natural history of SIRS (systemic inflammatory response syndrome). JAMA 1992; 268: $3452-3455$.

12. Van Tassell RL, Wilkins TD. Isolation of auxotrophs of Bacteroides fragilis. Can J Microbiol 1978; 24: 1619-1621.

13. Westphal O, Lüderitz O. Chemische Erforschung von Lipopolysacchariden gramnegativer Bakterien. Angew Chem 1954; 66: $407-417$.

14. Galanos $C$, Lüderitz $O$, Westphal $O$. A new method for the extraction of R lipopolysaccharides. Eur J Biochem 1969; 9: $245-249$.

15. Uchida K, Mizushima S. A simple method for isolation of lipopolysaccharides from Pseudomonas aeruginosa and some other bacterial strains. Agric Biol Chem 1987; 51 : 3107-3114.

16. Hancock IC, Poxton IR (eds). Bacterial cell surface techniques. Chichester, UK, Wiley: 1988.

17. Laemmli UK. Cleavage of structural proteins during the assembly of the head of bacteriophage T4. Nature 1970; 227: $680-685$.

18. Tsai C-M, Frasch CE. A sensitive silver stain for detecting lipopolysaccharides in polyacrylamide gels. Anal Biochem 1982; 119: 115-119.
19. Dubois M, Gilles KA, Hamilton JK, Rebers PA, Smith F. Colorimetric method for determination of sugars and related substances. Anal Chem 1956; 28: 350-356.

20. Chen PS, Toribara TY, Warner H. Microdetermination of phosphorus. Anal Chem 1956; 28: 1756-1758.

21. Lowry OH, Rosebrough NJ, Farr AL, Randall RJ. Protein measurement with the Folin phenol reagent. $J$ Biol Chem $1951 ; 193: 265-275$.

22. Galanos C, Lüderitz O. Lipopolysaccharide: properties of an amphipathic molecule. In: Rietschel ET (ed) Handbook of endotoxin vol 1. Amsterdam, Elsevier. 1984: 46-58.

23. Loppnow H, Brade H, Dürrbaum I et al. IL-1 induction-capacity of defined lipopolysaccharide partial structures. J Immunol 1988; 142: 3229-3238.

24. Fujiwara T, Nishihara T, Koga T, Hamada S. Serological properties and immunobiological activities of lipopolysaccharides from black-pigmented and related oral Bacteroides species. J Gen Microbiol 1988; 134: 2867-2876.

25. Allan E, Poxton IR. The influence of growth medium on serum sensitivity of Bacteroides. J Med Microbiol 1994; 41:45-50.

26. Lutton DA, Patrick S, Crockard AD et al. Flow cytometric analysis of within-strain variation in polysaccharide expression by Bacteroides fragilis by use of murine monoclonal antibodies. J Med Microbiol 1991; 35: 229-237. 